\title{
Immuno-chromatographic Test-strip for Skin Cathepsin L Analysis
}

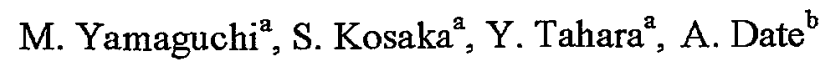 \\ ${ }^{\text {a }}$ Graduate School of Engineering, Iwate University, 4-3-5 Ueda, Morioka, Iwate 020- \\ 8551 Japan \\ ${ }^{\text {b }}$ Procter \& Gamble Japan K.K., 1-17 Koyo-cho Naka, Higashinada-ku, Kobe, 658-0032 \\ Japan
}

\begin{abstract}
The objective is to develop a methodology to analyze cathepsin $\mathrm{L}$ (Cat $\mathrm{L}$ ) activity derived from the stratum corneum as an index of skin conditions. In this paper, a disposable type immunochromatographic test-strip (test-strip) is proposed for Cat $\mathrm{L}$ analysis. A fabricated test-strip for Cat $\mathrm{L}$ analysis consists of a sample pad, a conjugate pad, a nitrocellulose membrane and absorption pad. After dropping a sample, it was needed $90 \mathrm{~s}$ to reach the solution at the test-line on the test-strip. Three min after dropping, a reddish purple colored band was appeared as the test-line. The band visually observed clearly when the concentration of Cat $L$ of the standard solution over $0.01 \mathrm{U} / 1$. It was indicated a possibility of the disposable type immuno-chromatographic test-strip for the analysis of Cat $L$ of skin.
\end{abstract}

\section{Introduction}

The analysis of stratum comeum components is a widely accepted method to determine skin health status. The cathepsin family is one of a metabolizing enzyme of skin cell and it includes aspartic protease cathepsin D (EC 3.4.23.5) and cysteine proteases cathepsin B (EC 3.4.22.1), H (EC 3.4.22.16) and L (EC 3.4.22.15) ${ }^{(1.2)}$. Cathepsin $\mathrm{L}(\mathrm{Cat} \mathrm{L})$ is a lysosomal cysteine protease with a major enzyme in intercellular protein catabolism ${ }^{(3)}$. Cat $\mathrm{L}$ also shows the most potent collagenolytic and elastinolytic activity in vitro of any of the cathepsins ${ }^{(4)}$. Cat $\mathrm{L}$ has been identified as a stratum corneum desquamation process-related enzyme ${ }^{(5)}$. Cat $\mathrm{L}$ is one of a metabolizing enzyme of skin and it concerned in the metabolism of melanin.

We have been investigating the relationship between the photo-stress of human skin and Cat $\mathrm{L}$. The objective is to develop a methodology to analyze Cat $\mathrm{L}$ activity derived from the stratum corneum as an index of skin conditions. In this paper, a disposable type immuno-chromatographic test-strip (test-strip) is proposed for Cat $\mathrm{L}$ analysis. In order to make possible collecting of stratum corneum easily, a test-stripping method was used.

\section{Materials and Methods}

\subsection{Collection of human skin sample}

First, the face of subjects were carefully washed with a facial cleansing soap (P\&G) and water of ambient temperature and wiped with a towel. Subjects were acclimated by sitting in an environmental room at temperature of $24^{\circ} \mathrm{C}$ and a relative humidity of $40 \%$. 
Twenty min after the washing of the face, the stratum corneum was collected using a tape stripping (D-Squame disk D100, Cuderm Co., TX) with a diameter of $22 \mathrm{~mm}{ }^{(\sigma)}$ (Fig. 1a). The tape stripping was affixed on the upper cheek surface for $30 \mathrm{~s}$ (Fig. 1b), after that it was pulled off the skin. Immediately after, the tape stripping was inserted into $750 \mu 1$ acetate buffer $(4 \mathrm{mM}, \mathrm{pH} 5)$ containing $0.1 \%$ triton $\mathrm{X}-100$. An ultrasonic wave was applied to the sample using an ultrasonic cleaner (2210DTH, Branson Ultrasonic Co., CT) for $30 \mathrm{~min}$ at $37^{\circ} \mathrm{C}$. A negative control ( $4 \mathrm{mM}$ acetic acid buffer solution, $\left.0 \mathrm{U} / \mathrm{l}\right)$, the Cat L standard solution $(0.010-1 \mathrm{U} / 1)$ and the human skin sample $(0.015$ and 0.020 $\mathrm{U} / 1$ ) were used for the evaluation of the test-strip.

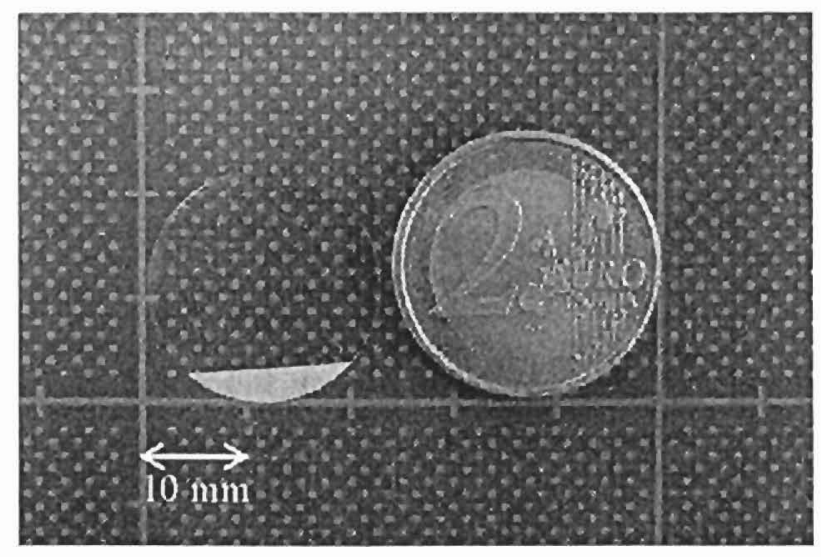

(a) A tape stripping

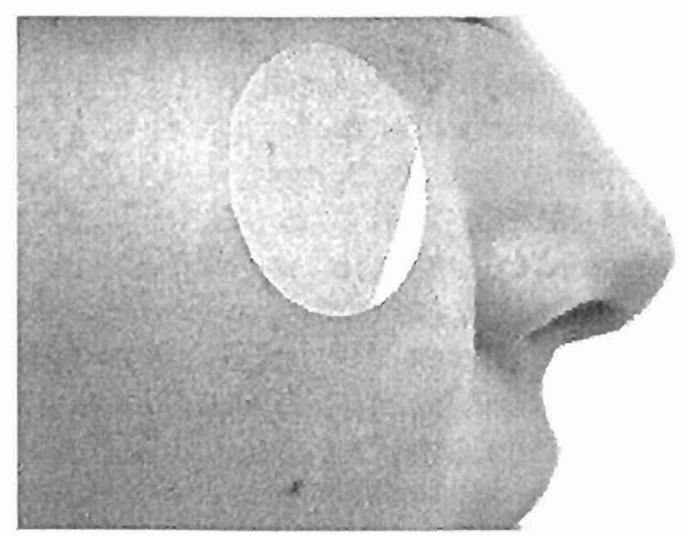

(b) Collection of human stratum corneum using a tape stripping

Fig. 1 External view of a tape stripping used for the collection of human stratum corneum. 


\subsection{Immuno-chromatographic Test-strip}

A fabricated immuno-chromatographic test-strip for Cat $\mathrm{L}$ analysis (test-strip) consisted of a sample pad $\left(5 \times 10 \times 0.83 \mathrm{~mm}^{3}\right.$, CFSP203000, Millipore Co., MA), a conjugate pad $\left(5 \times 5 \times 0.41 \mathrm{~mm}^{3}\right.$, GFCP103000, Millipore Co. $)$, a nitrocellulose membrane $\left(50 \times 5 \times 0.24 \mathrm{~mm}^{3}\right.$, HF12004XSS, Millipore Co. $)$ and absorption pad $(5 \times 5 \times$ $0.83 \mathrm{~mm}^{3}$, CFSP203000, Millipore Co., Fig. 2).

Cat $\mathrm{L}$ antibody labeled colloidal gold was prepared by mixing a colloidal gold solution $\left(O D_{520}=6\right.$, WRGH1, Wineredchemical Co., Japan), anti-human Cat L antibody (R\&D Systems, Inc., MN) and $20 \mathrm{mM}$ Tris- $\mathrm{HCl}$ buffer ( $\mathrm{pH} 9.8$ ) containing $2.5 \%$ casein. In order to make the conjugate pad, a filter paper was dipped in the Cat $\mathrm{L}$ antibody labeled colloidal gold (secondary antibody) solution then dried in an oven. The antihuman Cat $\mathrm{L}$ antibody $(0.5 \mathrm{mg} / \mathrm{ml})$ was immobilized on the nitrocellulose membrane in order to make a test-line. Finally, the nitrocellulose membrane was blocked against the nonspecific protein adsorption by immersion in $10 \mathrm{mM}$ phosphate buffer solution ( $\mathrm{pH} 7)$ containing $1 \%$ casein sodium, and incubated for $30 \mathrm{~min}$ at room temperature (Fig. 3a).

When $100 \mu \mathrm{l}$ sample is dropped on the sample pad, the impurities with large molecular weights are filtered by the sample pad. Immediately after, the sample solution dissolves the secondary antibody in it from the conjugate pad. The sample solution moves to the vertical direction on the membrane by capillary action and reach to a testline (Fig. 3b). The target molecule (Cat L, antigen) in the sample solution is immobilized with colloidal gold labeled antibody by the antigen-antibody complex reaction. If the colloidal gold agglutinates over a fixed density, the test line turns in red color (Fig. 3c).

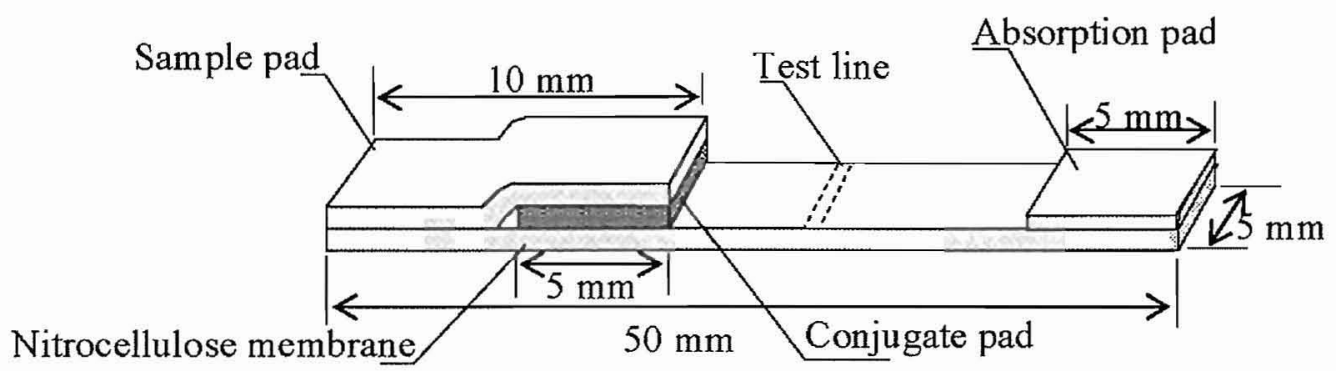

(a) Configuration of an immuno-chromatographic test-strip

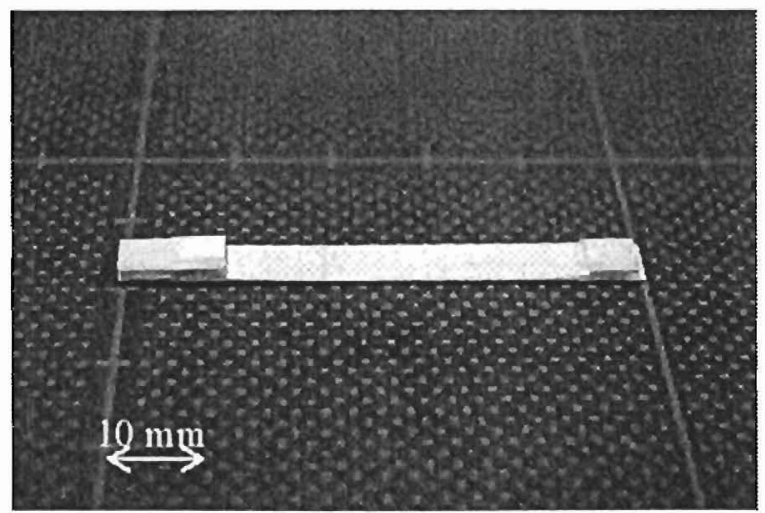

(b) External view of an immuno-chromatographic test-strip

Fig.2 External view of an immuno-chromatographic test-strip for Cat $\mathrm{L}$ analysis. 


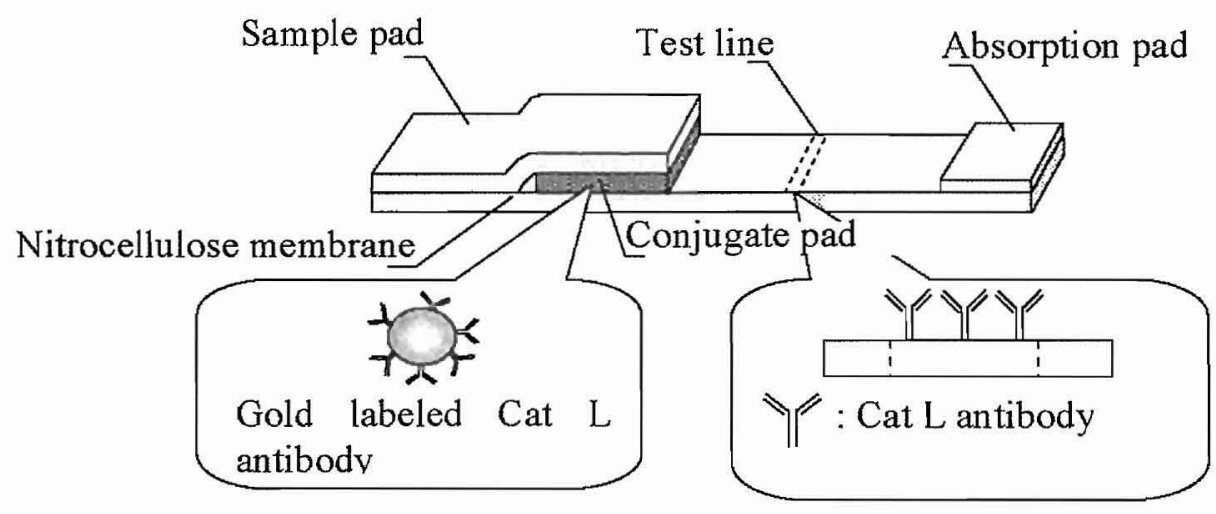

(a) Schematic of the immuno-chromatographic test-strip

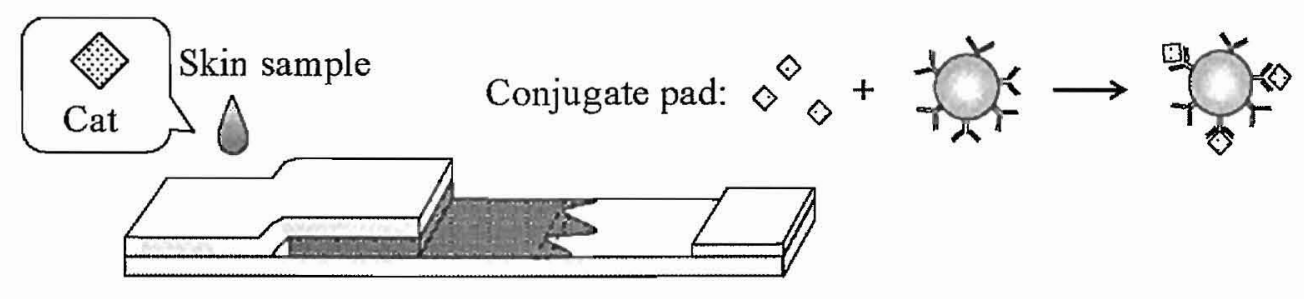

(b) Capillary action (chromatography)

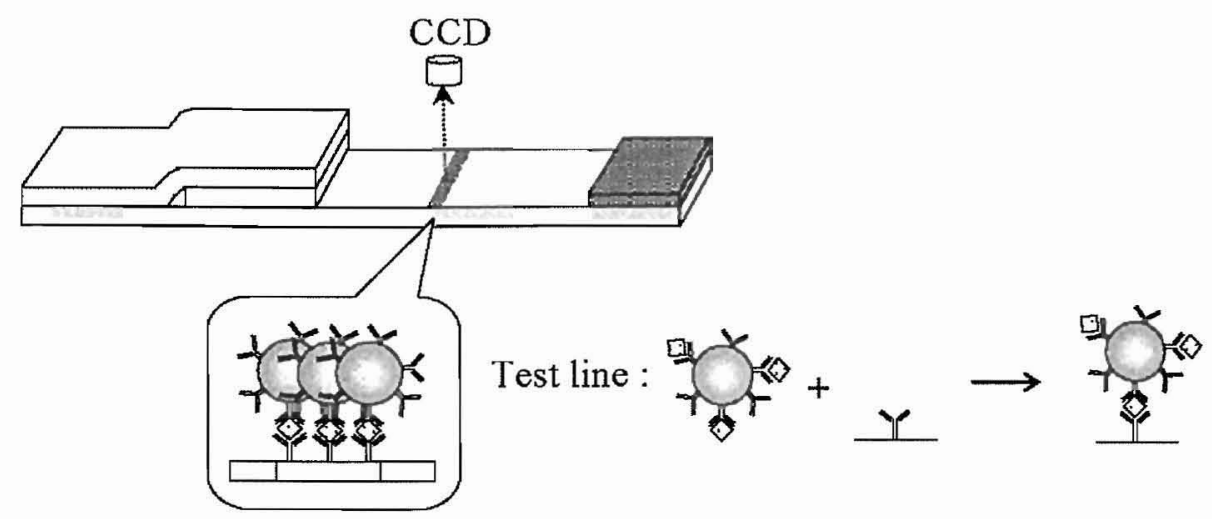

(c) Semi-quantitative analysis

Fig.3 Principle of colloidal gold-based immuno-chromatography. 


\subsection{Optical analyzer for Cat L Analysis}

An optical analyzer $\left(25.5 \times 26.5 \times 14.5 \mathrm{~cm}^{3}, 11 \mathrm{~kg}\right)$ was fabricated in order to analyze the Cat $\mathrm{L}$ test-strip (Fig. 4a). The fabricated optical analyzer consisted of an optical device that measured the optical density of a temperature control unit for the teststrip and a personal computer (Latitude D531, DELL Inc., TX) that display and record the data. A charge coupled device image sensor (CCD) unit was used as the optical device (Fig. 4b). When the Cat $\mathrm{L}$ test-strip was placed, the CCD illuminate vertically on to the test-strip. The density of the test line is measured by the CCD at the wavelength between $300-800 \mathrm{~nm}$.

The reflection raito $R$ of the test line was calculated using the following equation:

$$
R=\mathrm{S} / \mathrm{S}_{0}
$$

Where, $S$ : the amount of light received after reaction,

$S_{0}$ : the amount of light received before reaction.

The reflection ratio is then converted to optical density $(O D)$ using the following equation:

$$
O D=-\log (R)
$$

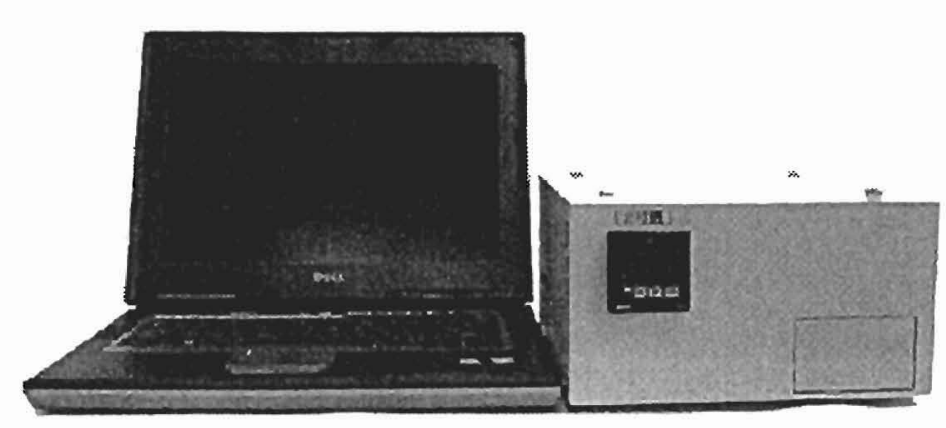

(a) An external view of the fabricated optical analyzer $\left(25.5 \times 26.5 \times 14.5 \mathrm{~cm}^{3}\right)$

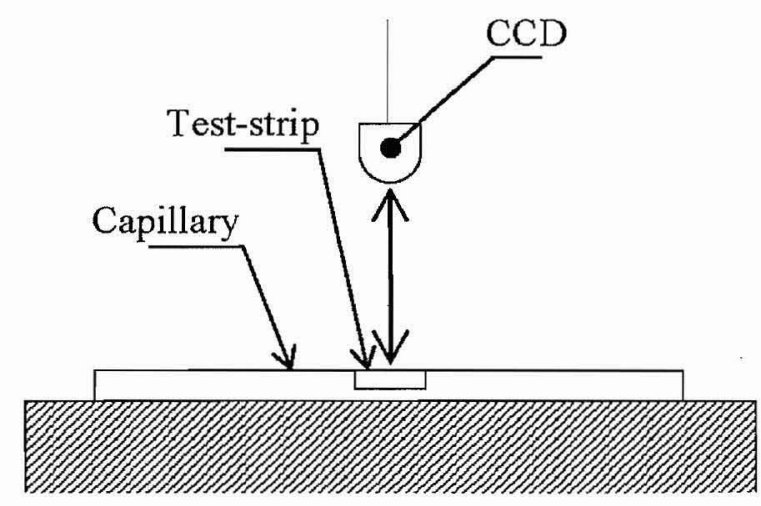

(b) The measurement principle

Fig.4 A fabricated optical analyzer for analysis of the test-strip. 


\section{Results and Discussions}

Cat $\mathrm{L}$ (mean $\pm \mathrm{SD}$ ) of the 20 healthy female adults $(20.9 \pm 1.0 \mathrm{yr})$ was $0.020 \pm 0.005$ $\mathrm{U} / 1$, and ranged between $0.015-0.031 \mathrm{U} / 1$.

After dropping the sample, it was needed $90 \mathrm{~s}$ to reach the solution at the test-line on the test-strip. Three min after dropping, a reddish purple colored band was appeared as the test-line. The band visually observed clearly when the concentration of Cat $\mathrm{L}$ of the standard solution over $0.01 \mathrm{U} / 1$ (Fig. $5 \mathrm{~b}, \mathrm{c}, \mathrm{d}$, e and $\mathrm{f}$ ). In the control $(0 \mathrm{U} / \mathrm{l})$, the test line did not turn in color (Fig. 5a).

Similarly, the band visually observed clearly when the concentration of $\mathrm{Cat} L$ of the human skin sample over $0.015 \mathrm{U} / 1$ (Fig. $4 \mathrm{~g}$ and $\mathrm{h}$ ). Cat $\mathrm{L}$ in the skin sample of human stratum corneum could be detected. It was suggested that the immuno-chromatographic test-strip might be used for the analysis of Cat $\mathrm{L}$ in skin.

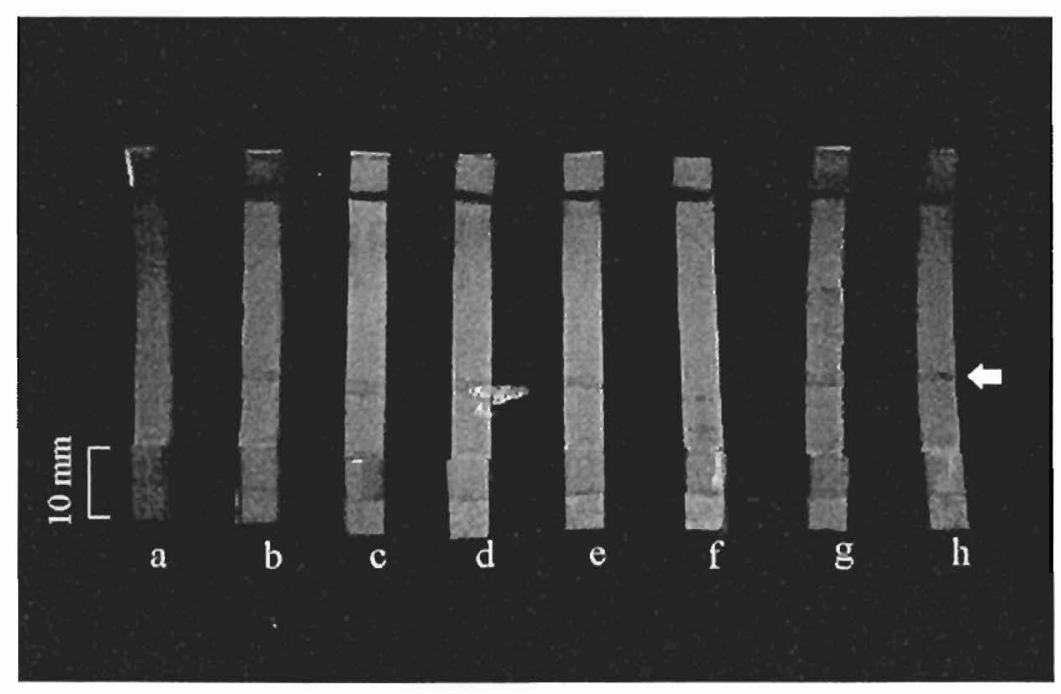

Fig.5 Analysis of CatL using the immuno-chromatographic test-strip. a; negative control (0 U/1), b; $0.01 \mathrm{U} / 1, \mathrm{c} ; 0.02 \mathrm{U} / 1, \mathrm{~d} ; 0.05 \mathrm{U} / 1$, e; $0.1 \mathrm{U} / 1, \mathrm{f} ; 1 \mathrm{U} / 1$ (b - f; standard solution), g; $0.015 \mathrm{U} / 1, \mathrm{~h} ; 0.02 \mathrm{U} / 1,(\mathrm{~g}-\mathrm{h}$, human skin sample), $\diamond ;$ Test line.

\section{CONCLUSION}

It was indicated a possibility of the disposable type immuno-chromatographic teststrip for the analysis of Cat $\mathrm{L}$ of skin. The fabricated test-strip was able to analyze visually over $0.05 \mathrm{U} / 1$ of Cat $\mathrm{L}$ within $3 \mathrm{~min}$. In addition, it was indicated that the fabricated test-strip can detected CatL from human stratum corneum, and the immunochromatographic test-strip could be useful for Cat $\mathrm{L}$ analysis. 


\section{REFERENCES}

1. Barrett AJ, Kirschke H. Methods Enzymol., 80 Pt C, 535 (1981).

2. Katunuma N, Towatari T, Kominami E, Hashida S, Takio K, Titani K. Acta Biol Med Ger., 40(10-11), 1419 (1981).

3. Mayer RJ, Doherty F. Fed Eur Biochem Soc., 198, 181 (1984).

4. Kirschke H, Kembhavi AA, Bohley P, Barrett AJ. Biochem J., 201(2), 367 (1982).

5. Bernard D, Méhul B, Thomas-Collignon A, Simonetti L, Remy V, Bernard MA, Schmidt R. J Invest Dermatol., 120(4), 592.(2003).

6. Voegeli R, Heiland J, Doppler S, Rawlings AV, Schreier T. Skin Res Technol., 13(3), 242 (2007). 